\title{
Algumas provocações sobre aprendizagem (e para além) para uma experiência docente em arte
}

\author{
Some provocations about learning (and beyond) for a teaching \\ experience in art
}

\section{Algunos avances sobre el aprendizaje (y más allá) para una experiencia docente en arte}

Lislaine Sirsi Cansi I

https://orcid.org/0000-000 I-8583-5290

\begin{abstract}
Resumo: Este artigo trata de uma experiência docente advinda de uma pesquisa finalizada de Mestrado em Artes Visuais, em que foi discutido sobre a poética na docência como proposta teórica para a sala de aula escolar a partir da prática do sujeito nomeado como "artista-professor". Aqui, pretende-se fazer algumas provocações sobre a linguagem da educação, especificamente no que concerne a questões sobre aprendizagem, articulando a poética na docência a elas e apresentando a experiência docente aplicada em sala de aula escolar, com estudantes de quintos anos de um colégio privado confessional cristão, por meio de uma prática educativa que teve como temática a Arte Moderna, restrita à Arte Abstrata. Como fundamentação teórico-metodológica serão utilizadas as vozes de autores como Biesta (2013), Larrosa (2015), Barros (1994), Arendt (2010; 2016), Kohan (2013), Osinski (200I) e Duarte Jr. (2000). Por fim, foi reconhecido que a arte abstrata possui características distintas e que há nela o pensamento da arte proposto pelo "artista-professor", sujeito desvelado na pesquisa de mestrado. Palavras-chave: Aprendizagem. Experiência docente. Arte abstrata.
\end{abstract}

Abstract: This article deals with a teaching experience arising from a completed Master's in Visual Arts research, in which poetics in teaching was discussed as a theoretical proposal for the school classroom based on the practice of the subject named as "artist-teacher". Here, it is intended to make some provocations about the language of education, specifically with regard to questions about learning, articulating the poetics in teaching to them and presenting the teaching experience applied in the school classroom, with fifth-year students of a high school Christian confessional, through an educational practice whose theme was Modern Art, restricted to Abstract Art. As a theoretical-methodological basis, the voices of authors such as Biesta (2013), Larrosa (2015), Barros (1994), Arendt (2010; 2016), Kohan (2013), Osinski (200I), Duarte Jr. (2000) will be used. Finally, it was recognized that abstract art has distinct characteristics and that there is in it the thought of art proposed by the "artist-teacher", subject unveiled in the master's research.

Keywords: Learning. Teaching experience. Abstract art.

Resumen: Este artículo trata sobre una experiencia docente que surge de una investigación realizada para la Maestría en Artes Visuales, en la que se discutió la poética en la docencia como propuesta teórica para la sala de

\footnotetext{
'Doutora em Educação pela Universidade Federal de Pelotas (PPGE/UFPel). Artista e professora de Artes Visuais. E-mail: lislaine_c@yahoo.com.br
} 
aula escolar a partir de la práctica de la asignatura denominada como "artista-docente ". Aquí, se pretende hacer algunas provocaciones sobre el lenguaje de la educación, específicamente en lo que se refiere a cuestiones sobre el aprendizaje, articulando la poética en la enseñanza y presentando la experiencia docente aplicada en sala de aula, con alumnos de quinto año de un colégio privado confessional cristiano, a través de una práctica educativa cuyo tema fue el Arte Moderno, restringido al Arte Abstracto. Como fundamento teórico-metodológico, las voces de autores como Biesta (2013), Larrosa (2015), Barros (1994), Arendt (2010; 2016), Kohan (2013), Osinski (200I) y Duarte Jr. (2000) será utilizado. Finalmente, se reconoció que el arte abstracto tiene características distintas y que en él está el pensamiento del arte propuesto por el "artista-maestro", tema desvelado en la investigación de la maestria.

Palabras clave: Aprendizage. Experiencia docente. Arte abstracto.

\section{Introdução}

A poética na docência diz respeito a uma proposta amplamente discutida em uma dissertação de Mestrado em Artes Visuais (CANSI, 2016). A reflexão é aportada através do sujeito que é artista e que é professor e que fundamentalmente ocupa, se ocupa e transita por entre esses dois territórios, o território das poéticas visuais e o território do ensino da arte, para se constituir no sujeito nomeado como "artista-professor". Tal sujeito se interessa pela inserção do pensamento da arte em sala de aula articulando a poética de algum artista na docência e não tão somente a sua poética como artista. É necessário salientar que o sujeito "artista-professor" não se encontra sozinho no espaço escolar já que ele atua junto aos enfrentamentos de seu grande campo, a Educação. Aqui, tais enfrentamentos dizem respeito à linguagem da educação, especificamente às questões referentes à aprendizagem.

Esse momento é tencionado por certo amontoado teórico, algumas provocações voltadas à linguagem da educação. Eis as primeiras partes desse texto, intituladas "Descomeço”, em que se busca pensar sobre aprendizagem, sobre aquilo que vem antes da aprendizagem, quem são os sujeitos que chegam ao espaço escolar e que ali permanecem e, "Para além da aprendizagem", em que se discute sobre o desaprender no campo da educação. Tais discussões são realizadas a partir de vozes de autores como de Gert Biesta (20I3), Jorge Larrosa (20I5), Hannah Arendt (20I0; 20I6), Walter Kohan (20I3), Dulce Osinski (200I), João Francisco Duarte Jr. (2000), Manoel de Barros (1994).

O terceiro momento refere-se à apresentação da experiência docente em sala de aula escolar, realizada com estudantes de seis turmas de quintos anos de um colégio privado confessional cristão, ○ Colégio São José, situado em Pelotas-RS. Trata-se de uma narrativa crítica sobre a referida prática educativa. A temática abordada diz respeito à Arte Moderna, restrita ao movimento abstracionista. $\mathrm{A}$ partir do pensamento da arte de artistas como Wassily Kandinsky (1866, Rússia - 1944, França), Piet Mondrian (1872, Holanda - 1944, EUA), Paul Klee (I879 - 1940, Suíça) e Jackson Pollock (1912 - 1956, EUA), a prática teve como objetivo geral desmistificar que tal arte é uma arte fácil de ser produzida e reproduzida.

Por fim, o último momento do texto diz respeito à amarração de saberes, em que se procura 
contemplar o referencial teórico-metodológico articulado à prática desenvolvida em sala de aula escolar. Nesse sentido, pretende-se expor nesse artigo uma experiência docente sobre arte no espaço escolar, lugar em que o "artista-professor" é atuante.

\section{“Descomeço"}

Inicio a ação de escrever esse texto a partir de uma paráfrase da poesia de Manoel de Barros (1994): "No descomeço era a aprendizagem". Ao considerar a compreensão da palavra "descomeço" empregada em sua poesia como aquilo que vem antes, aquilo que pode ser pré-requisito, aquilo que se ajunta para então vir a ser aquilo que é, sugiro pensar sobre a palavra aprendizagem para somente depois inserir o advérbio "além", discutido pelo autor e professor de Teoria e Política Educacional Gert Biesta (2013), em seu livro intitulado Para além da aprendizagem: Educação democrática para um futuro humano, obra de referência para essa discussão, desde o título do presente artigo.

Aprendizagem, aprendiz, desaprender, aprendente: todas essas palavras possuem o mesmo radical linguístico, a mesma origem etimológica, tornando claro e objetivo o sentido básico de cada termo. Aprendizagem, aprendiz, desaprender e aprendente são palavras advindas de aprender, "de ad, 'junto', mais prehendere, com o sentido de 'levar para junto de si', [...], em prae-, 'à frente', mais hendere, relacionado a hedera, "hera"'2, planta trepadeira que se agarra às paredes para poder crescer. Compreende-se que a palavra aprender denota uma relação conjunta entre o exterior e o interior do sujeito que aprende, constituindo certa apreensão dessa relação pelo sujeito e que, por isso, não pode ser descartada nem anulada do processo educacional. Salienta-se, aqui, que Biesta (2013) discursa sobre a morte do "sujeito". Nesse texto, no entanto, não existe a intenção de matar o “sujeito"; ele aparecerá com certa frequência, porém não carregará consigo o sentido da terminologia moderna, a da verdade; ele é entendido como sujeito em aberto.

É notório que ao cogitarmos algo sobre o espaço escolar a palavra aprendizagem apareça imediatamente em nossa mente, pois o pensamento da sociedade atual a prioriza. Basta lembrarmonos da pergunta frequente de pais ou responsáveis ao receberem os seus filhos ou entes queridos no final de um dia letivo: o que você aprendeu hoje? $\mathrm{Na}$ esteira desse raciocínio questiona-se sobre a linguagem da educação: o primado da comunidade escolar se direciona à educação ou à aprendizagem no espaço escolar ou educacional?

O professor de Filosofia da Educação Walter Kohan (2013, p. I) concorda com Biesta (2013) que "a linguagem da educação (a forma em que se fala de questões e problemas educacionais) tem sido

\footnotetext{
${ }^{2}$ Disponível em: http://origemdapalavra.com.br/site/palavras/aprendizagem/ Acesso em: 09 mar. 2017.
} 
encurtada a uma linguagem da aprendizagem". Esse movimento entre as linguagens minimiza (restringindo) o universo educacional - que é democrático - à aprendizagem. A aprendizagem como foco da educação pode tornar a instituição educacional um ambiente voltado ao mercado, ao capital, à troca: quem pode escolher por determinado tipo de aprendizagem, entendida como a melhor, mais garantida, compra-a, e assim define aquilo que será aprendido. A compra da aprendizagem também determina os sujeitos envolvidos: a instituição propicia a oportunidade, o professor é declarado o provedor e o facilitador, e o aluno, o consumidor. Na linguagem da aprendizagem, a educação (empresarial?) pode ser compreendida como técnica, já que ensinar torna-se sinônimo de apoio ao aprender. Eis uma questão cara a todos os sujeitos da classe docente que se sentem realmente responsáveis pela educação.

Por meio da linguagem da aprendizagem é possível pensar na construção de um sujeito para determinado mundo: um mundo em que se aprende a reter informações para momentos específicos (provas escolares, exames nacionais, concursos públicos). Um mundo em que se aprende a focar em determinada profissão (ser técnico, ser especialista); um mundo em que não é oportunizado ser o "sujeito da experiência" (LARROSA, 20I5), um mundo em que aprender, somente aprender, seria uma ação limitada e permanente para o sujeito.

O aprendiz pode ser considerado um sujeito que se adapta a esse mundo restrito da linguagem da aprendizagem. Pensa-se no sujeito aprendiz a partir da relação mestre-aprendiz que se instaurou no campo da Arte em certos (e longos) períodos da História da Arte, como na Arte Egípcia, na Arte Greco-Romana e na produção artística da Idade Média. A artista e professora de arte Dulce Osinski (200l) narra que a formação artística nesses períodos ocorria pela tradição, entendida como imitação, por convenções estéticas estritamente determinadas, pela excelência da técnica, tudo isso agregado à não permissão do surgimento de individualidades no processo formativo. Para aproximar a relação mestre-aprendiz de nosso tempo, Duarte Jr. (2000, p. 29) afirma em sua tese que "um mestre ensina ao aprendiz como ele deve ver e interpretar trabalhos e tendências artísticas, sem qualquer preocupação de como vem se dando sua percepção e sensibilidade cotidianas”. Distante ou próximo a nós, é possível considerar que o sujeito aprendiz aprenderia somente por meio da transmissão de conhecimento de seu mestre, sem ser "sujeito da experiência" (LARROSA, 20I5), sem alcance à educação do sensível, somente à educação racional ou a uma "comunidade racional". Biesta (20/3) indica que a "comunidade racional" é caracterizada por um modo comum de pensar a vida, em que há sentimento de pertencimento à comunidade e nela é estabelecida apenas uma voz representativa.

Voltando ao "sujeito da experiência", ele se define "não por sua atividade, mas por sua passividade, por sua receptividade, por sua disponibilidade, por sua abertura" (LARROSA, 20I5, p. 25- 
26). Ser "sujeito da experiência" é estar aberto à experiência para que algo nos aconteça ou nos toque: corresponde a estar disponível à desordem, à incerteza, à falta de racionalização ao sentir, à percepção, ao prazer corporal, às possibilidades intersticiais, à relatividade, a um novo olhar, à memória, à imaginação, à fantasia, ao lúdico, à valorização das pequenezas do mundo, aos sentidos (sem o compromisso com as palavras prévias), à “desterritorialização” (DELEUZE, 1997), à criação de outra territorialidade.

O sujeito aprendiz, desvinculado da "experiência", seria como o sujeito da fábrica que age mecânica e repetitivamente, possuindo pensamento igualitário, sem tempo livre em seu fazer para tentar pensar diferente, assumindo para si (talvez inconscientemente) o conceito de "corpo dócil" (FOUCAULT, 1987). Segundo Foucault (1987, p. II8), "é dócil um corpo que pode ser submetido, que pode ser utilizado, que pode ser transformado e aperfeiçoado”. Entende-se, nesse sentido, que são corpos que estão servindo ao capitalismo enquanto submissos aos convites do sistema do capital. Já, como aprendizes, são corpos submissos ao conhecimento do mestre, são corpos preocupados em empreender apreendendo informações, apenas consumindo informações, são corpos que não resistem ao sistema educacional.

Corpos resistentes ao sistema são corpos que se deixam experienciar, que param para pensar, que desejam, que se reconfiguram, que se modificam, que permitem o surgimento de novas verdades e que não só aprendem.

A experiência, a possibilidade de que algo nos aconteça ou nos toque, requer um gesto de interrupção, um gesto que é quase impossível nos tempos que correm: requer parar para pensar, parar para olhar, parar para escutar, pensar mais devagar, e escutar mais devagar; parar para sentir, sentir mais devagar, demorar-se nos detalhes, suspender a opinião, suspender $o$ automatismo da ação, cultivar a atenção e a delicadeza, abrir os olhos e os ouvidos, falar sobre o que nos acontece, aprender a lentidão, escutar aos outros, cultivar a arte do encontro, calar muito, ter experiência e dar-se tempo e espaço (LARROSA, 20I5, p. 25).

Inserida a "experiência" de que trata Larrosa à linguagem da educação, arrisco aqui provocar, ao incluir o sujeito do campo da Psicopedagogia, o sujeito aprendente. Anterior a isso, é fundamental frisar que:

A Psicopedagogia busca compreender a subjetividade constituída pelo desejo de saber e pela demanda de conhecimento [...]. O objeto da Psicopedagogia não é, então, o conteúdo ensinado ou o conteúdo aprendido ou não aprendido; são os posicionamentos ensinantes e aprendentes e a intersecção problemática entre o conhecer e o saber (ANDRADE, 2006, s/n).

De acordo com os estudos do campo referido, o aprendente seria aquele sujeito que se relaciona com o sujeito ensinante, não equivalente às relações mestre-aprendiz e professor-aluno 
(ANDRADE, 2006). A diferença de sentido se encontra na posição do sujeito. $O$ aprendente indica um modo subjetivo de situar-se no mundo, ele se constitui a partir da articulação entre o sujeito desejante (Psicanálise) e o sujeito cognoscente (Pedagogia), por meio de qualquer vínculo. Desse modo, o ensinante poderia ser qualquer pessoa, um professor, um colega, um amigo, um familiar. Ressalto aqui a importância e o papel fundamental, intransferível e insubstituível do professor no espaço educacional: o sujeito ensinante não se compara ao professor e à sua função na sala de aula já que esta faz referência a "lugares objetivos em um dispositivo pedagógico" (ANDRADE, 2006, s/n) e a sujeitos do conhecimento. Cabe ao professor no espaço educacional desequilibrar o sistema cognitivo de seu aluno para que este possa reequilibrá-lo por meio da construção do conhecimento. $O$ professor, portanto, tem responsabilidade educacional (e nada pretendo dizer acerca das demandas não educacionais transferidas ao professor pela sociedade atual, sendo a sua função primeira aquilo que importa). Avançando: o sujeito ensinante "ocupa a posição do suposto Saber, re-conhecendo o desejo de conhecer no sujeito aprendente" (ANDRADE, 2006, s/n). Desse modo, sinaliza a potência a respeito do desejo do sujeito aprendente. Compreendendo que o sujeito aprendente, se alimentado por seu desejo de saber, possa fazer pausas - ou os gestos de interrupção citados por LARROSA (20I5) - para pensar, sentir e agir lentamente, acaba sendo "sujeito da experiência".

Biesta (2013) dá preferência ao âmbito educacional e não ao sistema ensino-aprendizagem, refletindo sobre o papel da educação em uma sociedade democrática abarcando, nesse caso, sujeitos democráticos. Dito isso, procurarei a partir desse momento pensar para "além" da aprendizagem, o que implica refletir acerca do sistema educacional e em suas questões, em uma sociedade democrática. Começarei pelo que entendo como "desaprender".

\section{“Para além” da aprendizagem}

Considerando a concepção de escola de Jan Masschelein e Maarten Simons (2015) como um espaço de "suspensão", de "profanação", de "atenção" e de "amor público", espaço esse de pensamento para poder pensar o mundo, sobre as coisas do mundo, sobre si mesmo, sem convenções, sem tempo radicalmente marcado no tempo cronológico e com individualidade, é possível cogitar sobre "desaprender" no espaço escolar, pois, em nosso tempo sócio-histórico, não nos é permitido apenas reproduzir conhecimento, como indicou Osinski (200I). Desaprender não significa a morte do aprender, mas um ressuscitar para as novas ou outras coisas do mundo, como sugere novamente $\circ$ poeta Manoel de Barros (1994). E mais: desaprender remete a um ato político para enfrentar a crise educacional.

Em $A$ crise na educação Hannah Arendt (2016, p. 132) afirma que "uma crise só se torna um 
desastre quando respondemos a ela com juízos pré-formados, isto é, com preconceitos. Uma atitude dessas não apenas aguça a crise como nos priva da experiência da realidade e da oportunidade por ela proporcionada à reflexão". A crise assim pensada, crise sem preconceitos, se assemelha com a concepção chinesa, na qual a crise é uma crase, significando mistura ou fusão, dita na língua oriental “wei-ji, locução composta pela junção dos ideogramas perigo e oportunidade” (DUARTE JR., 2000, p. 72). Crise sem preconceitos, ajuntando risco e esperança, dá margem para decisões com perspectivas positivas, pois "O que importa é aprender a esperar" (BLOCH, 2005, p. 13).

Duarte Jr. (2000) reflete sobre a crise atual a partir do modo de agir e de pensar da modernidade e traz uma abordagem para o campo da Arte através da educação do sensível. Desaprender, ação depreendida do âmbito do saber sensível, é a palavra-chave para a sua compreensão e para o discernimento daquele que a vê, sente, interage e aprecia. Penso que é a partir do descabido, daquilo que nos silencia na Arte, que podemos desordenar, despir, delirar, desconhecer, descontinuar, descobrir, desequilibrar, desviar, desdobrar, desvelar. Assim como os produtores de arte, estas possibilidades motivadas pelo des-, " [...] sabotam, subvertem, quebram as possibilidades de um sentido narrativo único. Desestabilizam nossas compreensões da vida e injetam sutilezas, incertezas, sons que se recombinam e se estranham entre si” (CANTON, 2009, p. 5I).

Do mesmo modo que nas ações dos produtores de arte, desaprender poderia ser uma alternativa de ação manifestada na abordagem sensível, reflexiva e ética de Joseph Jacotot, o "mestre ignorante”, da obra de Rancière (2002). O "mestre ignorante" questiona seus alunos incessantemente à tríplice questão: “o que vês? o que pensas disso? o que fazes com isso?" (RANCIÈRE, 2002, p. 35), e afirma que os alunos devem ver tudo por eles mesmos, até o infinito. Kohan (2013, p. 4) conclui que “dessa maneira, o professor ignora o que os alunos aprendem”. Tal fato se assemelha à proposição de Biesta (2013, p. 103) ao pensar a educação a partir da "compreensão desconstrutiva da educação", sendo necessário, deste modo, repensar as ações pedagógicas a partir da impossibilidade. Enfatizo aqui que a desconstrução se situa também no contexto do des-, de desaprender: não como algo negativo ou opositor, mas que denota afastamento, separação, a fim de avistar outras oportunidades.

Ao imergir na desconstrução da educação é plausível enxergar nos sujeitos para "além" de aprendizes e de aprendentes. É concebível perceber as crianças e os adolescentes escolares como seres de novos inícios e que vêm ao mundo de forma única e singular (ARENDT, 2016). Biesta (20I3) considera este contexto baseado em três conceitos advindos da relação educacional, a saber: confiança (relação professor-aluno permeado por riscos e desafios), violência (relação da educação com o mundo externo e a sua interferência na vida do aluno) e responsabilidade (pela subjetividade de alguém, do iniciante, do aluno, do outro, daquele que não se conhece). É possível alargar essa percepção a todos nós como iniciantes e iniciadores, independentemente do tempo-espaço em que nos encontramos, ao 
concordar com Arendt quando ela diz que "[...] somos todos capazes de inícios" (ARENDT apud BIESTA, 20I3, p. II4).

Considerada a natalidade, segundo Arendt (2016), a essência da educação, quando a criança vem ao mundo de modo único e singular, ela se coloca em uma comunidade calcada pela pluralidade e pela diferença, repleto por Outros, não sendo, portanto, uma "comunidade racional" (BIESTA, 20I3). É nesse momento que entram os iniciadores, sujeitos responsáveis por oportunizar inícios às crianças que chegam ao mundo, implicando em torná-las "presença”.

Tornar-se presença não é simplesmente um processo de se apresentar ao mundo. Consiste em começar num mundo cheio de outros iniciadores, de tal maneira que não sejam obstruídas as oportunidades para que outros iniciem. Tornar-se presença é, portanto, uma apresentação a outros que não são como nós (BIESTA, 2013, p. 75).

No espaço educacional esse sujeito que apresenta a outro, que oportuniza a "presença" ao outro, é o professor. O professor é o responsável em ensinar à criança como o mundo é e com autoridade (ARENDT, 2016). O professor ensina por meio da "ação", atividade que "[...] passa diretamente entre os homens" (ARENDT apud BIESTA, 20I3, p. III). A ação com o outro, ação política e condição humana da pluralidade proposta por Arendt (2010), é o que confere liberdade (no sentido político - não sentimental) à criança recém-chegada, ao iniciante, à pessoa democrática. Podese pensar que só somos livres quando em ação com o Outro e em um espaço mundano, espaço este caracterizado pela pluralidade e pela diferença, pela outridade. A liberdade também é possibilitada pela atividade de "visitar", isto é, "ver com nossos próprios olhos a partir de uma posição que não é a nossa" (BIESTA, 20I3, p. 124).

Fica claro, a partir desse contexto, que a questão educacional concerne à ação e à possibilidade de ação no espaço educacional, e que os alunos, os recém-chegados, podem ser pessoas democráticas (BIESTA, 2013). Considerando que "a ação não consiste apenas em início, consiste também nas maneiras pelas quais esses inícios são adotados pelos outros” (BIESTA, 2013, p. 183), retornarei ao "artista-professor", sujeito que deu voz à abertura desse texto desvelado na pesquisa de Mestrado em Artes Visuais, e apresentarei uma possibilidade de ação em sala de aula voltada a uma educação democrática. É sobre isso que tratam as próximas partes desse artigo.

\section{Experiência docente: desmistificando a arte abstrata}

O “artista-professor", sujeito que pertence a dois territórios, o território da produção poética e o território do Ensino da Arte, carreia consigo, em sala de aula, questões pertinentes ao pensamento da Arte: o processo de produção artística, os conceitos que a fundamentam e o seu contexto espaço- 
temporal. Nesse sentido e em se tratando da sala de aula, é necessário oportunizar espaço de discussão e de reflexão para promover a criação crítica e contextualizada. A singularidade do aluno e o modo subjetivo para pensar e agir são essenciais para o processo. Dessa forma, considera-se que a interação com o outro promova condições para a ação e para ser sujeito democrático, podendo experienciar o des-. Ressalto: a interação com o outro não é exclusivo ao espaço educacional, mas uma responsabilidade social. Assim é possível perceber que os iniciantes no espaço educacional podem ir para "além" de aprender a ler, a escrever, a somar, a dividir e a desenhar - podem ir para "além" da apreensão de técnicas e de conteúdo - podem agir, com liberdade, estando com o outro e sendo sujeitos democráticos.

A poética na docência está em mim, sendo ela que me constitui como a profissional que sou, atuante no espaço educacional, desde antes da pesquisa de Mestrado em Artes Visuais (CANSI, 20I6). Porém, foi a partir da ação de dissertar sobre essa temática que pude ter consciência e compreensão de minha prática pedagógica. Portanto, a pesquisa foi o meio para que eu pudesse me tornar "artistaprofessora" e buscar caminhos teórico-metodológicos para a sala de aula, considerando quem são os sujeitos que ocupam as classes desse espaço, bem como o que desejam (se aprendizes, se aprendentes, se sujeitos da experiência, se sujeitos democráticos, se sujeitos iniciados - não necessariamente sendo somente um sujeito, apartado um do outro). É a partir desse contexto que surgiu a prática educativa realizada em sala de aula escolar, após a finalização da pesquisa de Mestrado, narrada a seguir.

Tal prática ocorreu no Colégio São José, situado em Pelotas (RS), no componente curricular Arte, para estudantes de seis turmas de quintos anos do ensino fundamental, realizada no segundo trimestre de 2019. Além da missão de formação religiosa, não no sentido de aceitar somente a comunidade católica cristã em seu seio pedagógico e, sim, promover a vivência da fraternidade e da solidariedade e educar pessoas capazes de comunhão consigo, com os outros e com Deus, o colégio visa formar cidadãos autônomos, conscientes e competentes, capazes de buscar respostas aos desafios da comunidade e de seu tempo. A respeito da classe discente, foi trabalhado com um total de 139 estudantes, com faixa etária regular para o adiantamento, quinto ano, entre 10 e II anos de idade. Os estudantes eram muito agitados e demandavam atividades pedagógicas diferenciadas para que pudesse haver interesse, concentração, desejo de ação para apreciar, fazer e socializar a produção artística (BARBOSA, 2012). O intervalo de tempo em que a prática foi realizada foi de aproximadamente quarenta e cinco dias, sendo a carga horária semanal igual a dois períodos de cinquenta minutos cada.

Retornando à compreensão da poética na docência, o "artista-professor" se interessa pela inserção do pensamento da arte em sala de aula, articulando a poética de algum artista na docência e não tão somente a sua poética como artista. Entretanto, esta inserção não é aleatória e sim contextualizada. A temática da prática - Arte Abstrata - não foi eleita por mim, nem pelos discentes, 
portanto, não foi uma escolha: era presença no currículo, tema obrigatório a ser ensinado. $O$ tema foi indicado no currículo, mas não havia ali clareza quanto ao "o que" e "como" ensinar. Em se tratando de um colégio privado, em que viagens nacionais e internacionais fazem parte da vida cotidiana dos estudantes, optei em conversar com eles acerca de seus conhecimentos e vivências com a arte moderna. Com tal conversa somada à liberdade dada pelo setor de coordenação pedagógica para o cumprimento da prática pedagógica, o "o que" foi se estruturando. A direção do "como" ensinar estava em mim, a partir da pesquisa de mestrado em artes visuais concernente à poética na docência.

Durante a conversa com os estudantes foi perceptível identificar que a Arte Abstrata era considerada como uma arte fácil, sem variação, sem pensamento de arte, sem objetivo, sem observação do mundo pelo artista. Percebi preconceitos já estabelecidos (com crianças de 10 e II anos!) quanto a esse movimento artístico da arte moderna e questionei: como ensinar, como aprender, como propor experiência, como desaprender? Juntei pesquisa com a necessidade e o desejo dos discentes e objetivei desmistificar a caracterização indicada por eles, buscando reconhecer que ela possui características distintas e que há nela o pensamento da arte. Foi proposto aprender, desaprender e experienciar.

Avançando: vivemos o tempo do instantâneo, do passageiro, do imediato (BAUMAN, 200I), e essas são características típicas de uma sala de aula escolar contemporânea. Tornava-se urgente considerar a reflexão sobre o "sujeito da experiência" de Larrosa (20I5) que implica em parar para observar, ver, pensar, sentir. Nesse contexto, e junto à estrutura oferecida pelo colégio, o passo a passo teórico-metodológico foi eleito. Nesse caso, optou-se pela utilização da lousa digital como recurso principal para a apresentação teórica da arte abstrata. Os estudantes nasceram no mundo digital e é nesse mundo em que vivem, desejavam viver e param para ver, pensar, sentir: junto às telas. O conceito, os artistas e as obras foram apresentados na lousa, em Power Point produzido por mim. Havia acesso direto à internet para a busca de vídeos, em que a linguagem utilizada fosse naturalmente familiar e acessível aos estudantes. Toda a parte teórica foi posta em discussão no grande grupo para, em seguida, haver a proposição da prática artística, individual ou coletiva. Salienta-se que registros fotográficos ou fílmicos não foram realizados.

Para começo de conversa sobre as peculiaridades da prática educativa é necessário enfatizar que o Abstracionismo é um movimento artístico do início do século $X X$ entendido como uma forma de arte que não representa objetos próprios da nossa realidade, aqueles que nomeamos cotidianamente, e que $\circ$ artista abstrato utiliza pontos, linhas, cor e formas irregulares e/ou geométricas (PRETTE, 2008). Tendo isso em mente, pensa-se na numerosa quantidade de artistas abstratos existentes no contexto na História da Arte e nos motivos da escolha de apenas alguns deles para virem a ser estudados em sala de aula escolar. Os artistas eleitos foram selecionados pela sua 
importância para a História da Arte no que concerne à originalidade, à diversidade conceitual e plástica, sendo eles: Wassily Kandinsky (1866, Rússia - 1944, França), Piet Mondrian (I872, Holanda - 1944, EUA), Paul Klee (1879 - 1940, Suíça) e Jackson Pollock (1912 - 1956, EUA). Depois de compreendido o conceito da Arte Abstrata, os artistas citados foram abordados um a um, entre teoria e prática, silêncio e discussão, experiência e socialização. Começarei com Kandinsky.

Wassily Kandinsky não existia até então no repertório artístico-cultural dos estudantes, aqui entendidos como os "iniciados". Ele foi apresentado como professor e como artista através de um vídeo de pouco mais de dez minutos, encontrado na plataforma youtube. O vídeo abarca minimamente a biografia e a obra do artista em tom de retrospectiva. Foi enfatizada a relação de sua produção artística abstrata com a linguagem da música, em que a expressão das emoções por meio da linha e da cor, libertas de sua função primeira, se torna relevante. Kandinsky era um sinesteta: "A palavra sinestesia é hoje utilizada tanto na ciência quanto nas artes para descrever experiências de união sensorial" (BERGANTINI, 2019, p. 225). No caso do artista referido, ele associava o som à cor. Tratase da sinestesia metafórica, sob a qual se "[...] busca traduzir ritmos musicais em elementos pictóricos" (BERGANTINI, 2019, p. 230). Esse é o pensamento da arte de Kandinsky que instigou a classe discente.

A proposição da prática artística foi justamente replicar o pensamento da arte de Kandinsky: através da Sinfonia $n^{\circ} 40$ de Wolfgang Amadeus Mozart os estudantes deveriam sentir o ritmo da música e desenhar uma composição não figurativa, utilizando ponto, linha e forma. O momento de parar de desenhar não foi imposto, cada estudante colocaria um ponto final em seu desenho no momento em que desejasse. Em seguida, a inserção da cor foi solicitada. Outra vez, realizada por associação. Em uma turma, um discente sugeriu a Sinfonia $n^{\circ} 5$ de Ludwig van Beethoven, já que esse era o sujeito de seus estudos musicais afora ao colégio. Tais aspectos metodológicos apontam para a busca de uma educação democrática pelo "artista-professor".

Observou-se que somente dois estudantes não desenvolveram a prática artística: eles relataram que ficaram nervosos e não conseguiram se expressar em tempo hábil. Ao observá-los, percebi a negação por meio da desistência. Não houve abertura à prática e aos sentidos para ouvir o ritmo musical e transformá-lo em desenho, portanto, estes estudantes não tiveram o desejo do conhecimento para serem sujeitos aprendentes e não se tornaram "sujeitos da experiência". Reforço que não houve marcação do tempo cronológico na execução da atividade e que a música foi repetida inúmeras vezes, de acordo com a necessidade dos estudantes. Saliento que não se trata de falta de aprendizagem, já que houve negação à prática, e sim, às questões do universo educacional indicadas por Arendt (20I0; 20I6), Biesta (20I3), Larrosa (20I5) e Duarte Jr. (2000).

O segundo artista, Pieter Cornelis Mondrian, também fez uso da sinestesia em suas obras (BERGANTINI, 2019), porém buscou-se nele um segundo pensamento da arte, aquele que concerne 
à racionalidade. Diferente de Kandinsky, Mondrian já era conhecido pelos estudantes, não o pensamento de sua arte e sim o produto da arte, a sua obra em sua maturidade artística. Entretanto, foi identificado que o conhecimento era o da obra pela obra. Seguindo: foi mostrado aos estudantes um vídeo curto sobre a biografia e a vida do artista, mas, nesse estudo, as imagens estáticas foram as referências: na lousa da sala de aula teve uma mostra de imagens da obra do artista, de seu processo de abstração, desde a pintura da árvore com todos os seus detalhes morfológicos que indicam que aquilo representaria uma árvore, até a sua obra mais popular e reproduzida, a obra estruturada com linhas pretas verticais e horizontais e formas pintadas com as cores primárias (vermelha, azul e amarela). Salientou-se a busca incessante do artista por equilíbrio.

A prática artística proposta seria seguir o passo a passo metodológico do artista: observar uma árvore e desenhá-la, para, em seguida, fazer o processo de abstração do referencial. Imaginei que o desenho de observação seria realizado em algum espaço externo ao colégio, em uma praça em frente a ele ou em um pátio interno localizado em sua fachada. Essa etapa não foi possível, pois o medo da cidade falou mais alto (BAUMAN, 2007; 2009). O colégio localiza-se em um local próximo ao centro da cidade e ao seu redor centros universitários são alocados, gerando movimento constante de transeuntes e no trânsito. Frente a esse impasse, tal etapa foi adaptada e virou tema de casa. Sendo crianças de 10 e II anos, entendo que essa etapa teve perdas cognitivas, já que faltou o olhar do "artista-professor" para mediar a atividade.

Deu-se continuidade ao segundo momento da prática e uma folha na dimensão A4 foi dividida em oito partes iguais. Nesses espaços ocorreu o processo de abstração de uma árvore observada e desenhada, esta reproduzida na primeira parte das oito citadas. $O$ desenho seguinte teria que ser realizado de acordo com a observação do desenho anterior e assim sucessivamente. Somente o desenho da última parte da folha deveria ser finalizado com as cores utilizadas pelo artista. Percebi a dificuldade das crianças para desenvolver essa etapa. Muitos não compreendiam de que maneira poderiam racionalmente abstrair a forma da árvore, geometrizar as suas linhas orgânicas anteriormente observadas. Outros, pintaram as árvores desenhadas com as cores observadas na própria árvore, restritas ao estereótipo da dupla verde e marrom. Para finalizar o estudo desse artista foi proposto para os estudantes, de forma optativa, que aplicassem o último desenho, o finalizado, em algum objeto. Não foi dado prazo, nem marcada alguma data. Alguns alunos fizeram e mostraram os seus objetos "mondrianos". Entendo que tais estudantes poderiam ser os sujeitos aprendentes tratados por Andrade (2006), já que apresentaram um modo subjetivo de se situarem no mundo, por meio de seu desejo de saber aplicado em objetos pessoais.

O terceiro artista, Paul Klee, também foi professor, aqui eleito porque o pensamento da arte 
está no próprio artista, no modo de ser artista, produtor de arte como "antena do mundo", atento permanentemente a ele, para imerso nele poder produzir a sua poética. Considera-se na escolha desse artista que eles - os artistas - "captam do ar partículas de sentido às quais, nós homens comuns, não percebemos" (REQUIÃO, 20I3, p. II4). Explico: dois vídeos foram expostos, sendo o primeiro sobre a biografia e obra do artista, e o segundo acerca de seus ensinamentos como professor na Escola da Bauhaus, sugeridos no vídeo como cinco lições para ser artista. No primeiro vídeo, salientou-se o impacto da cor em sua obra quando o artista viajou para um país africano. No segundo, a discussão girou em torno das lições para ser artista, sendo elas: I. Leve a linha para passear; 2. Observe o aquário; 3. Desenhe o sistema circulatório; 4. Pese as cores; 5. Estude os grandes. Tais lições foram entendidas para que o artista em formação pudesse vir a ser artista seria necessário que ele conseguisse: trabalhar livre e espontaneamente com a linha no desenho, elemento básico da linguagem visual; observar a natureza e se inspirar nela, nesse caso, no movimento dos peixes nadando no aquário; estudar o sistema da natureza, a exemplo, as ramificações das plantas, dos rios e o sistema circulatório do sangue em nosso corpo; perceber que as cores pesam visualmente em uma composição, portanto, seria fundamental compreender o círculo cromático e a harmonização das cores; e estudar os artistas consagrados na História da Arte, formar repertório visual e produzir artisticamente, tendo a obra desses artistas como referência. Durante esse momento, identifiquei que o peso das cores é um estudo avançando para o adiantamento (quinto ano). Nesse sentido, foi sugerido que o peso fosse aquilo que eles gostariam que chamasse mais atenção na composição.

A proposição da prática artística foi uma produção coletiva. Em dupla, trio ou quarteto, os estudantes deveriam discutir acerca das lições para ser artista, elencar no mínimo três delas e fazer um desenho ou uma colagem tendo tais lições como referências. A produção artística foi realizada em uma folha com dimensão $A 2$, aproximadamente. Os estudantes apresentaram a sua produção no grande grupo, em sala de aula, argumentando sobre as lições escolhidas e sobre aquilo que os colegas viam na folha. Nesse momento, mais que outros, os estudantes tornaram-se "presença" (ARENDT, 2010), eis a ação democrática oportunizada pelo "artista-professor", principalmente pela atividade de "visitar" (BIESTA, 20I3). No concernente às lições, a linha foi levada para passear em todas as produções. A lição que se fez rara foi a número cinco: a abordagem de obras dos grandes mestres foi difícil por questões técnicas e interpretativas. É necessário frisar que um estudante encontrou em sua casa um livro sobre a obra do Kandinsky e foi esse o artista de referência para o seu grupo, possibilitando que o mesmo fosse um grupo de aprendentes.

O último artista, Jackson Pollock, foi escolhido pelo pensamento da arte condizente com o gestual, com a relação corpo-obra. Para esse estudo, no primeiro momento, foram mostradas várias obras do artista na lousa e as suas características, incluindo a escala como elemento de análise, a saber: 
uso da técnica do action painting (pintura de ação), caracterizada pela presença de movimento, energia e velocidade; uso da técnica do drip painting (gotejamento); aplicação espontânea da tinta; uso de cores variadas (obras multicoloridas); presença de automatismo surrealista e abstrato. Em seguida, um vídeo curto sobre o artista em processo foi exibido. Nele, o artista pintava caminhando sobre uma grande tela utilizando a técnica do gotejamento.

A prática artística inicialmente era "pintar como Pollock”: em grupo, utilizando papel kraft em grande dimensão e abusando das técnicas utilizadas pelo artista. Individualmente, uma parte do papel seria recortada, para então, trabalhar nela. A proposição objetivava proporcionar que os estudantes pudessem sair de suas classes, de seu suporte cotidiano, e experienciar uma atividade lúdica de forma coletiva, explorando a relação corpo-obra. Além disso, teriam o embate do enfrentamento com os colegas na escolha da parte a ser recortada e finalizada individualmente. Tal proposição não foi possível por motivos estruturais: o colégio não possuía sala de arte e no momento de realização da prática não foi encontrado local adequado. Assim sendo, houve um segundo plano, a proposição de um desenho cego: sem tinta, sem o gestual do corpo sobre a folha no chão, sem a técnica de gotejamento. $A$ ação e o movimento do corpo ficaram restritos às coisas feitas no cotidiano escolar, o corpo sobre a mesa, sem enfrentamentos com o outro. Para finalizar o desenho cego, muitas cores foram utilizadas referenciando Pollock. Nesta proposição os estudantes experienciaram em parte o pensamento da arte de Pollock, contudo, ela não deixou de abarcar uma educação democrática.

Estudar arte moderna não foi uma escolha, repito: constava no currículo como conteúdo obrigatório. Entretanto, ajuntando pesquisa e abertura dos discentes, sendo esses iniciantes e/ou aprendentes, foi possível pensar com/sobre/em arte, independentemente de ela ser do nosso tempo sócio-histórico e oportunizar espaço para uma educação mais democrática, para "além" do aprender, demonstrado a seguir.

\section{Amarrando saberes}

Intentando evidenciar a aplicação da poética na docência faz-se necessário demonstrar tal processo por meio de uma articulação entre a prática pedagógica anteriormente narrada e o referencial teórico-metodológico problematizado.

Na sala de aula escolar há sobremaneira uma relação relevante entre professor e estudantes. O professor é entendido como um sujeito que desequilibra o sistema cognitivo de seu aluno para que este possa reequilibrá-lo por meio da construção do conhecimento, tendo responsabilidade educacional. Já, o estudante é compreendido como sujeito iniciado (ARENDT, 2016) ou aprendente (ANDRADE, 2006). Ambos levam a sua bagagem para o espaço escolar. 
No que refere a este artigo, o professor é nomeado como "artista-professor", pois pertence a dois territórios do campo da Arte, o da produção poética e o do Ensino da Arte. Ele transita entre esses territórios e conduz a sua prática educativa a partir da poética na docência, em que aborda o pensamento da arte de algum artista na sala de aula escolar. Este é o seu referencial. Além disso, o "artista-professor" considera os enfrentamentos e as questões relacionadas à linguagem da educação. Nesse contexto, houve a preocupação durante a experiência docente não apenas com a aprendizagem, e sim com o conceito de experiência de Larrosa (2015), com o engajamento dos estudantes, bem como com a sua receptividade, a abertura ao novo, aos sentidos e com liberdade de pensamento para criar durante a prática educativa.

No caso dos estudantes, iniciados ou aprendentes, agrupados no quinto ano de um colégio privado, eles levaram para dentro da escola concepções e vivências adquiridas e interiorizadas por meio de outras instituições (escolar, familiar). Em se tratando do tema trabalhado, o descomeço para os estudantes era a ideia pré-concebida de que a arte abstrata dispensaria técnica e pensamento em sua criação. Trata-se do universo da linguagem da aprendizagem: eles aprenderam a pensar dessa forma, mesmo que tal compreensão a respeito do tema discutido seja entendida como um estereótipo sobre o abstracionismo.

No espaço escolar é oportunizado acesso ao conhecimento de novos assuntos temáticos e, da mesma forma, é proposto ressignificar o aprender e o apreender de alguma concepção interiorizada para além dos muros da escola. Esta questão era a fresta necessária para o desenvolvimento da poética na docência, sendo a prioridade o universo educacional, que é democrático, tratado por Kohan (20/3) e Biesta (20I3), ensejando, para tal, o surgimento da individualidade no processo formativo (OSINSKI, 200I), da percepção e das sensibilidades cotidianas tendo alcance à educação do sensível (DUARTE JR, 2000) e sendo sujeito da experiência (LARROSA, 20I5). Tudo isso, distante da noção de comunidade racional citada por Biesta (2013).

Neste cenário, a experiência docente narrada denotou tempo livre para pensar, sentir, criar, para que os estudantes pudessem realmente se aproximar do pensamento do artista estudado, este liberto do tempo cronológico. É notório que quando o artista se encontra em seu ateliê, ele assume para si outro tempo, o tempo de sua produção poética que demanda pausas para pensar, sentir, criar, analisar, reconfigurar. Não se trata do tempo que corre no relógio e, sim, do gesto de interrupção (LARROSA, 20I5).

Aos alunos não cabia a pretensão de criar ou reproduzir tal qual a obra de arte exposta e dialogada. A meta foi buscar aplicar a poética na docência buscando uma educação democrática por meio da ação, da atividade de visitar, da presença, da experiência, da educação sensível, do desejo de saber. Por fim, os estudantes tornaram-se "sujeitos da experiência" já que se mostraram receptivos e 
abertos ao pensamento da arte dos artistas citados. Eles se manifestaram disponíveis à desordem, aos sentidos, à imaginação, a um novo olhar. Sem corpos dóceis, de modo geral, foram corpos resistentes ao sistema, que não somente aprenderam, mas que se deixaram experienciar e que se modificaram.

\section{Algumas considerações}

O propósito desse artigo foi pensar para "além" da aprendizagem, sugerindo provocações a partir dela sem anulá-la. A aprendizagem é elemento fundamental em uma sala de aula. Refletir e considerar quem são os sujeitos ali presentes, se são aprendentes, aprendizes, iniciados, sujeitos democráticos e/ou sujeitos de experiência altera o processo que se constrói com o campo da Educação, nesse caso, na atuação do sujeito nomeado como "artista-professor". No que concerne ao nosso tempo sócio-histórico e ao campo da Arte - propositivo, amplo e aberto -, o sujeito aprendiz pode ser descartado, pois é tempo de dar espaço à percepção e sensibilidade cotidiana e à construção de subjetividades.

Nesse contexto, a poética na docência foi uma importante proposição teórica para que o despudesse ocorrer em sala de aula. A poética na docência implica em oportunizar espaço para o pensamento da arte, torná-lo acessível, possível, compreensível. O desaprender propôs o "para além" da aprendizagem: a desconstrução da educação oportunizou para os estudantes a ludicidade, a experiência consigo e com o outro, pois desestabilizou certezas, desmitificando conceitos já estruturados tangíveis à temática estudada.

Por fim, a narrativa apresentada indica que é possível aprender a desaprender em sala de aula escolar. Não posso afirmar que os estudantes aprenderam quem são os artistas estudados ou se eles sabem pronunciar os seus nomes, ou se sabem identificar a sua obra dentre a numerosa quantidade de arte abstrata existente e relevante para a História da Arte. $O$ que realmente importa e aqui é necessário frisar é que os "iniciados" e os "aprendentes" desaprenderam, experienciaram, compartilharam "experiência", tornaram-se presença e se colocaram no mundo como sujeitos democráticos.

\section{Referências}

ANDRADE, M. S. de. Ensinante e aprendente: a construção da autoria de pensamento. Construção psicopedagógica, São Paulo, v. I4, n. II, dez. 2006. Disponível em: http://pepsic.bvsalud.org/scielo.php?script=sci_arttext\&pid=SI4I 569542006000 I00005\&lng=pt\&nrm=iso Acesso em: II mar. 2017.

APRENDIZAGEM. Disponível em: http://origemdapalavra.com.br/site/palavras/aprendizagem/ Acesso em: 09 mar. 2017. 
ARENDT, H. A condição humana. II ed. Rio de Janeiro: Forense Universitária, 2010.

ARENDT, H. A crise na Educação. In: ARENDT, H. Entre o passado e o futuro. São Paulo: Editora Perspectiva, 2016, p. I31 - |46. Disponível em: https://docero.com.br/doc/8n58I80 Acesso em: 09 mar. 2017.

BARBOSA, A. M. As mutações do conceito e da prática. In: BARBOSA, A. M. (Org.). Inquietações e mudanças no ensino da arte. São Paulo: Cortez, 20I2, p. 13 - 27.

BARROS, M. de. O livro das ignorãças. São Paulo: Civilização Brasileira, 1994.

BAUMAN, Z. Confiança e medo na cidade. Rio de Janeiro: Jorge Zahar, 2009.

BAUMAN, Z. Modernidade líquida. Rio de Janeiro: Jorge Zahar, $200 \mathrm{I}$.

BAUMAN, Z. Tempos líquidos. Rio de Janeiro: Jorge Zahar, 2007.

BERGANTINI, L. P. Sinestesia nas artes: relações entre ciência, arte e tecnologia. ARS, ano 17, n. 35, p. 225-238, 2019. Disponível em: https://doi.org/I0.I 1606/issn.2 I78-0447.ars.2019.15I267 Acesso em: II jan. 202I.

BIESTA, G. Para além da aprendizagem: Educação democrática para um futuro humano. Belo Horizonte: Autêntica Editora, 2013.

BLOCH, E. O princípio esperança I. Rio de janeiro: Ed UERJ Contraponto, 2005.

CANSI, L. S. Poética na docência [corpo e território]. 2016. Dissertação (Mestrado em Artes Visuais) - Programa de Pós-Graduação em Artes Visuais, Centro de Artes, Universidade Federal de Pelotas, Pelotas, 2016. Disponível em: http://guaiaca.ufpel.edu.br/handle/prefix/3680_Acesso em: 05 maio 2016.

CANTON, K. Narrativas Enviesadas. Coleção: Temas da Arte Contemporânea. São Paulo: WMF Martins Fontes, 2009.

DELEUZE, G. In: BOUTANG, P.-A. O Abecederário de Gilles Deleuze. Entrevistas feitas com Gilles Deleuze por Claire Parnet e filmadas nos anos 1988-1989. Montpamasse, 1997. (vídeo).

Online. Transcrição completa do vídeo disponível em: http://stoa.usp.br/prodsubjeduc/files/262/10I5/Abecedario+G.+Deleuze.pdf Acesso em: 05 jan. 2015.

DUARTE JR., J. F. O sentido dos sentidos: a educação (do) sensível. 2000. Tese (Doutorado em Educação) - Programa de Pós-Graduação em Educação, Faculdade de Educação, Universidade Estadual de Campinas, Campinas, 2000. Disponível em:

http://www.repositorio.unicamp.br/handle/REPOSIP/253464 Acesso em: 01 jul 2014.

FOUCAULT, M. Vigiar e punir: nascimento da prisão. Tradução de Raquel Ramalhete. Petrópolis: Vozes, 1987.

KOHAN, W. O. Notas para uma política do aprender. In: Congresso de Educação Básica: Qualidade na Aprendizagem (COEB). Florianópolis: Prefeitura Municipal de Florianópolis, 2013, p. I 6. 
LARROSA, J. Tremores. Tradução de Cristina Antunes e João Wanderley Geraldi. Belo Horizonte: Autêntica, 2015.

MASSCHELEIN, J.; SIMONS, M. Em defesa da escola: uma questão pública. Tradução de Cristina Antunes. Belo Horizonte: Autêntica, 2015.

OSINSKI, D. R. B. Arte, História e Ensino: uma trajetória. São Paulo: Cortez, $200 I$.

PRETTE, M. C. Para entender a arte: história, linguagem, época, estilo. São Paulo: Globo, 2008.

RANCIÈRE, J. O mestre ignorante: cinco lições sobre a emancipação intelectual. Tradução de Lilian do Valle. Belo Horizonte: Autêntica, 2002.

REQUIÃO, R. A. Na literatura (como na arte), a experiência do viver com: algumas passagens.

Paralelo 3I, edição 0I, p. 108-I27, dez. 20I3. Disponível em:

https://periodicos.ufpel.edu.br/ojs2/index.php/paralelo/article/view/3950 Acesso em: 16 ago. 2015.

Recebido em: 21 de janeiro de 2021.

Versão corrigida recebida em: 27 de agosto de 202I.

Aceito em: 27 de agosto de 2021 .

Publicado online em: 18 de fevereiro de 2022. 